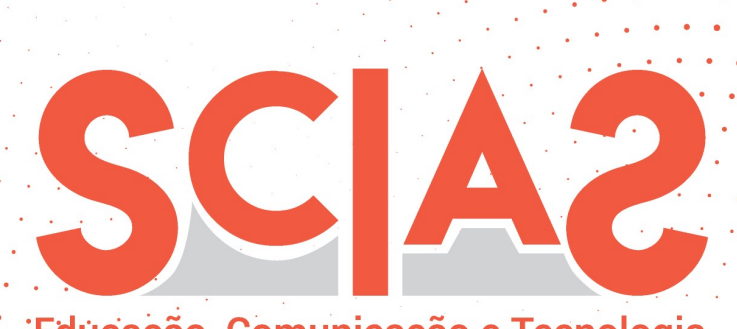

'Edúçaçã̃o, Comunicação e Tecnologia

\title{
Atribuição BB CY 4.0 \\ Ensino emergencial a distância durante pandemia de COVID-19: Perspectivas sobre uso da ferramenta Google Classroom e privacidade de dados
}

Michelle Alves da Silva ${ }^{1}$ Ágnes Cássia Grillo² Ana Elisa Sobral Caetano da Silva Ferreira3 3

\section{Resumo}

O presente relato tem como objetivo descrever a experiência do uso da ferramenta Google Classroom e G Suite for Education durante o período de isolamento social decorrente da pandemia ocasionada pela COVID-19. Em um exercício de reflexão desencadeado pelos dados apresentados no projeto Educação Vigiada, as três pesquisadoras debruçar-se-ão sobre a prática docente realizada na Educação Básica, nível fundamental II. O uso de Tecnologias Digitais de Informação e Comunicação (TDIC) na Educação não é novidade, entretanto, o atual momento fez com que a utilização de determinadas plataformas que trabalham segundo a lógica do Capitalismo de Vigilância (ZUBOFF, 2019) adentrassem o ambiente escolar sem que houvesse um amplo debate da comunidade. Esse relato apresenta-se como uma possibilidade de reflexão de futuras práticas que usam TDIC, considerando a problemática da mineração de dados, o uso da imagem, direitos autorais, política de privacidade e aumento da jornada de trabalho feminina.

\section{Palavras-chave}

Capitalismo de Vigilância. COVID-19. Ensino remoto emergencial. Google Classroom. Tecnologias Digitais de Informação e Comunicação.

Recebido em: 30/07/2020

Aprovado em: 22/12/2020

${ }^{1}$ Professora na Prefeitura Municipal da Estância Balneária de Itanhaém. Mestre em Biologia Aplicada - ramo Ecologia, Biodiversidade e Gestão de Ecossistemas pela UA, Portugal. Bacharel e Licenciada em Ciência Biológicas pela UNISANTA, Santos/SP.

E-mail: michelle.alves@educaita.com.br

${ }^{2}$ Professora de Língua Portuguesa pela Prefeitura Municipal da Estância Balneária de Itanhaém e mestranda do Departamento de Teoria Literária e Literatura Comparada da USP. Possui graduação em Letras (Português e Inglês) pela Universidade Católica de Santos e Pós-graduação (Lato Sensu) em Literatura Inglesa pela Faculdade São Luís.

E-mail: agnescassia@usp.br

3 Professora no quadro permanente do Instituto Federal de São Paulo, Campus Cubatão. Mestre em Educação pela UFSCar, doutoranda em linguística pela mesma instituição. Visitor scholar na universidade de Berkeley, California (2018-2019). Pesquisa capitalismo de vigilância e governamentalidade algorítmica na perspectiva da análise de discurso.

E-mail: anaelisaferreira@ifsp.edu.br 


\title{
Remote Emergency Education during the COVID-19 pandemic: Perspectives on the use of Google Classroom tool and data privacy
}

\begin{abstract}
This paper describes the experience of using Google Classroom tool and G Suite for Education package during social isolation because of the COVID-19 pandemic. Reflecting on the data presented at the Project Educação Vigiada, three female researchers will discuss on teaching practices to primary school. The usage of Digital Information and Communication Technologies (DICT) in Education is not a novelty, however, the use of some platforms that work according to the logic of Surveillance Capitalism (ZUBOFF, 2019) entered the school environment without an extensive community debate due to the pandemic. This report presents itself as a possible deliberation on future practices when using DICT, considering the problem of data mining, image rights, copyright, privacy policy, and women's increasing workload.
\end{abstract}

\section{Keywords}

Surveillance Capitalism. COVID-19. Remote Emergency Education. Google Classroom. Digital Information and Communication Technologies. 


\section{Introdução}

"[...] today our societies are threatened as the division of learning drifts into pathology and injustice at the hands of the unprecedented asymmetries of knowledge and power that surveillance capitalism has achieved."

Shoshana Zuboff, "The Age of Surveillance Capitalism"

Em dezembro de 2019, um surto de pneumonia causada pelo novo coronavírus (SARS-CoV-2) era relatado na cidade de Wuhan, localizada na região central da China. Uma doença infecciosa posteriormente denominada de síndrome respiratória aguda grave do coronavírus 2 (COVID-19) e que em menos de cinco meses já havia afetado mais de 210 países, tornando-se uma pandemia, trazendo consequências devastadoras (HE et al, 2020; LAM et al, 2020; WU et $a l, 2020)$ e que segundo a historiadora e antropóloga brasileira Lilia Schwarcz (2020) representaria um desfecho simbólico do século XX.

O vírus rapidamente espalhou-se pela Ásia e Europa assolando países como Itália, onde são 35.000 mortes registradas e 245.00o infectados em um período de quatro meses. A região da Lombardia tornou-se o epicentro da doença, com o notório aumento exponencial dos casos após o governo local resistir às medidas de isolamento social4, havendo até mesmo campanha publicitária (Milano non si ferma) contra o estabelecimento de uma quarentena 5 devido a preocupação com os impactos econômicos que uma paralisação traria.

O primeiro caso da COVID-19 confirmado no Brasil, segundo website do Ministério da Saúde (BRASIL, 2020), ocorreu no estado de São Paulo, divulgado no dia 26 de fevereiro de 2020, sendo que o paciente relatou viagem para a Itália. O Brasil já registrou 2.555.518 de pessoas infectadas pelo novo

\footnotetext{
4 ALESSI, G. Itália pagou preço alto ao resistir a medidas de isolamento social para conter coronavírus. El País. Disponível em:

<https://brasil.elpais.com/internacional/2020-03-25/italia-pagou-preco-alto-aoresistir-a-medidas-de-isolamento-social-para-conter-coronavirus.html>. Acesso em: 23 jul. 2020.

5 Campanha publicitária da prefeitura de Milão: Milano NON si ferma. Disponível em: <https://www.youtube.com/watch?v=GroNsrz7W3s\&feature=youtu.be >. Acesso em: 23 jul. 2020.
} 
coronavírus, com 90.188 de óbitos ${ }^{6}$ até o dia 29 de julho, tornando-se o segundo país no mundo 7 com o maior número de casos confirmados, e mais um epicentro da doença ${ }^{8}$. Segundo o boletim do Conselho Nacional de Secretários de Saúde (CONASS), São Paulo é o estado com os mais elevados números de infectados e letalidade no Brasil.

O surto de COVID-19 já demonstrou que nenhuma economia atingirá as metas previstas para 2020. No Brasil, por exemplo, a onda de desemprego e desaceleração já atinge mais de 14 milhões de pessoas, segundo IBGE (Instituto Brasileiro de Geografia e Estatística). No primeiro trimestre, o instituto registrou um aumento de 1,2 milhão, representando no total 12,9 milhões de desempregados em todo o país9.

A desigualdade não é somente financeira, mas também tecnológica. A China e a Coréia do Sul, por exemplo, adotaram mecanismos de vigilância baseados em dados biométricos que auxiliaram na contenção da epidemia, no entanto, esse tipo de vigilância sacrifica a privacidade individual em prol da saúde coletiva, questão já debatida por Harari.

Humanos e máquinas poderão se fundir tão completamente que os humanos não serão capazes de sobreviver se estiverem desconectados da rede. Estarão conectados desde o útero, e, se em algum momento da vida você optar por se desconectar, as companhias de seguro talvez se recusem a lhe fazer um seguro de vida, empregadores talvez se recusem a empregá-lo, e serviços de saúde talvez se recusem a cuidar de você. Na grande batalha entre saúde e privacidade, a saúde provavelmente vencerá sem muito esforço (HARARI, 2018, p. 109).

\footnotetext{
${ }^{6}$ Brasil passa de 90 mil mortes pelo novo coronavírus; 6 estados têm alta de óbitos. Disponível em: <https://g1.globo.com/bemestar/coronavirus/noticia/2020/07/29/casos-e-mortespor-coronavirus-no-brasil-em-29-de-julho-segundo-consorcio-de-veiculos-deimprensa.ghtmll>. Acesso em: 30 jul. 2020.

7 Painel de controle da Universidade Johns Hopkins, dos Estados Unidos. Disponível em: https://coronavirus.jhu.edu/map.html. Acesso em: 28 jul. 2020.

${ }^{8}$ FONSECA, P. Brasil profundo se torna epicentro da Covid-19 e capitais podem sofrer "tsunami" em efeito bumerangue. Disponível em:

<https://economia.uol.com.br/noticias/reuters/2020/o6/26/brasil-profundo-setorna-epicentro-da-covid-19-e-capitais-podem-sofrer-tsunami-em-efeitobumerangue.htm>. Acesso em: 19 jul. 2020.

9 IBGE. Disponível em: <https://www.ibge.gov.br/explica/desemprego.php>. Acesso em: 24 jul. 2020.
} 
Com o intuito de controlar melhor a epidemia do que a Europa e Américas, tais governos validam esse tipo de fiscalização, que poderá ser utilizado mesmo sem nenhuma ameaça a integridade física da população, sob o pretexto de prevenção de novas pandemias e epidemias.

Apesar de não ter os mesmos recursos de vigilância que os países asiáticos, alguns estados brasileiros, como Pernambuco e Rio de Janeiro, também adotaram a tecnologia digital como forma de monitoramento frente à emergência sanitária ${ }^{10}$.

A lógica da vigilância como meio de controle não é restrita à área da saúde, tampouco trata-se de uma questão nova. O conceito panóptico, explorado por Foucault (1987), demonstra que controle e poder fazem parte do gerenciamento social disciplinar. Entretanto, a novidade é que o avanço da tecnologia digital permite não só um controle dos corpos, mas também da mente, como defende Han (2018) em sua tese sobre psicopoder:

Hoje uma nova mudança de paradigma se realiza. O panóptico digital não é uma sociedade disciplinar biopolítica, mas sim uma sociedade da transparência psicopolítica. E no lugar de biopoder entra o psicopoder. A psicopolítica está em posição para, com a ajuda da vigilância digital, ler e controlar pensamentos [...] o psicopoder está em condições de intervir nos processos psicológicos (HAN, 2018, p. 253, grifos do autor).

O psicopoder de Han aponta o quão perigoso é o total acesso a dados pessoais que deveriam ser restritos aos usuários das tecnologias digitais, já que tais dados permitem possibilidades de controle sem precedentes, tanto por empresas privadas quanto por governos. Porém, frente a uma pandemia, a privacidade individual deixa de ser um direito fundamental e o controle da doença torna-se prioritário, como afirma Harari, abrindo portas para que tal vigilância seja constante, tornando-se a regra e não a exceção.

${ }^{10}$ Tecnologia ajuda poder público e população no combate à pandemia. Disponível em: <https://g1.globo.com/pe/pernambuco/noticia/2020/o7/18/tecnologia-ajuda-poderpublico-e-populacao-no-combate-a-pandemia.ghtml>. Acesso em: 19 jul. 2020. 
O governo do estado de São Paulo, um dos que adotou a vigilância por meio do sistema de localização global, fez parceria com operadoras de telefonia como Oi, Claro e Vivo, para monitorar seus usuários quando decretou quarentena por meio do decreto 64.881 do dia 22 de março. Assim, a partir do dia 24 do mesmo mês, todas as atividades com grande número de pessoas estavam suspensas, diversos tipos de trabalhos migraram do atendimento presencial para um tipo de atendimento on-line, inclusive as instituições educacionais que passaram a utilizar tecnologias digitais como forma específica de ensino.

Vivemos em uma sociedade onde as tecnologias digitais de comunicação e informação (TDIC) estão cada vez mais presentes em diversos espaços, sejam eles de trabalho, lazer ou educação. Aparelhos portáteis e potentes, como smartphones e tablets, conectam aqueles que têm acesso a todo tipo de informação disposta na rede mundial de computadores (World Wide Web).

Tais aparelhos permitem que alguns tipos de trabalho sejam feitos em home office durante a pandemia a fim de conter o contágio; entretanto, isso significa que o ambiente doméstico torna-se também o espaço de trabalho tendo impactos para todos os integrantes da família, mas principalmente para mulheres.

Por ser transmissível pelo ar e pelas superfícies de contato, o processo de higienização no ambiente doméstico tornou-se mais intenso: nas compras, nas correspondências, na lavagem de roupas e calçados, e da própria moradia, tais tarefas consomem até quatro horas diárias com procedimentos específicos para evitar o contágio ${ }^{11}$.

Essa sobrecarga de trabalho evidencia ainda mais as responsabilidades das mulheres: elas dedicam em média 8,2 horas semanais a mais que homens nas atividades de cuidados de pessoas e da casa ${ }^{12}$, dados de pesquisa entre maio e

${ }^{11}$ Gênero, quarentena e COVID-19: por uma crítica ao trabalho doméstico. Por Joana das Flores Duarte, 2020. Disponível em:<https://www.clacso.org/genero-quarentenae-covid-19-por-uma-critica-ao-trabalho-domestico/>. Acesso em: 21 jul. 2020. ${ }^{12}$ Quais os impactos da pandemia sobre as mulheres. Por Joana das Juliana Domingos de Lima, 2020. Disponível 
junho evidenciam que $52 \%$ das mulheres estão com sobrecarga de trabalho (DE JESUS e MYRRHA, 2020).

Nós, mulheres, fazemos parte de um grupo historicamente discriminado na sociedade patriarcal e a pandemia agrava discrepâncias. Segundo Butler,

A desigualdade social e econômica garantirá que o vírus discrimine. O vírus por si só não discrimina, mas os humanos certamente o fazem moldados pelos poderes entrelaçados do nacionalismo, racismo, violência contra mulheres, xenofobia e capitalismo (BUTLER in AMADEO, 2020, p. 60, tradução nossa).

Com mais tempo de permanência em casa devido a quarentena, as mulheres que são mães tendem a ser mais solicitadas pelos filhos, principalmente na área da educação, uma vez que o processo de aprendizagem não se dá mais na escola, e sim na frente de telas. Além disso, para as mulheres que são professoras, a demanda de conhecimento de TDIC modificou drasticamente o modo de trabalho, uma vez que as atividades pedagógicas realizadas no ensino presencial devem ser adaptadas para o uso remoto, baseando-se nas plataformas digitais.

Para que fizéssemos uso das plataformas adotadas por nossa instituição de ensino, tivemos que estudar os manuais e tutoriais, além das horas para a correção das atividades, atendimento a dúvidas e comentários dos discentes, que também não sabiam manusear as novas ferramentas. Mesmo com o apoio da Secretaria de Educação Municipal, oferecendo suporte técnico e capacitação sobre as ferramentas da Google, coube aos professores dedicar grande parte do seu tempo livre ao aprendizado das TDIC.

O objetivo deste relato de experiência é refletir sobre as adaptações que foram necessárias para o ensino remoto emergencial durante o período de suspensão de aulas presenciais na pandemia de COVID-19 no Brasil. Debateremos a utilização dos aplicativos educacionais da empresa Google e os impactos do emprego das TDIC na atividade docente, tendo como referência o exercício de duas professoras da rede municipal de Itanhaém, litoral do estado de São Paulo.

em:<https://www.nexojornal.com.br/expresso/2020/o3/24/Quais-os-impactos-dapandemia-sobre-as-mulheres/>. Acesso em: 21 jul. 2020. 
Neste relato, também serão abordados duas questões que estão intrinsecamente ligadas à experiência das docentes: o uso e o armazenamento de dados feito pelas grandes empresas de tecnologia, amplamente relatado no projeto Educação Vigiada (https://educacaovigiada.org.br), e a expropriação de direitos típica da lógica do capitalismo de vigilância.

\section{Relato de experiência}

Em sincronia com as medidas tomadas em âmbito estadual, as prefeituras dos municípios que integram a Região Metropolitana da Baixada Santista, sancionaram ações conjuntas e coordenadas para o enfrentamento da emergência de saúde pública homologando os decretos 3.899 e 8.889 em 16 de março.

A fim de não interromper o ano letivo de 2020, o município de Itanhaém passou a empregar o ensino remoto, em caráter emergencial. As escolas do ciclo básico fazem uso da ferramenta Google Sala de Aula (Google Classroom) (GSA), que pertence à plataforma de ensino $G$ Suite for Education. O GSA é uma sala de aula virtual, que apresenta integração com outras ferramentas da Google, como o Documentos Google, Google Gmail, Google Agenda e Google Drive.

$\mathrm{O}$ presente relato refere-se à experiência profissional vivenciada durante $\mathrm{o}$ período do teletrabalho, entre março e julho de 2020 e discorre sobre a prática de duas professoras, uma de Língua Portuguesa e outra de Matemática, no emprego emergencial de TDIC no ensino a distância. Os dados aqui relatados refletem a vivência do ensino online, das fontes de materiais de estudos e de discussões entre as autoras desse relato.

As atividades do ensino remoto estão sendo realizadas com alunos de 11 a 14 anos de idade do ensino fundamental de uma escola municipal localizada na cidade de Itanhaém, no litoral de São Paulo. Iniciadas em 23 de abril e sem data para o término até o momento, as disciplinas mencionadas utilizam a ferramenta GSA e os seus recursos para o desenvolvimento das aulas durante o período de isolamento social. 
O uso do GSA e das ferramentas incorporados da própria empresa são amplamente utilizadas pelas docentes, tais como: Documentos Google, Planilha Google, Apresentação Google, Formulários Google, Desenhos Google, Google My Maps, Google Sites, Google Jamboard, Google Gmail, Google Agenda e Google Drive. Além disso, são usadas ferramentas, aplicativos, extensões e outras plataformas que possuem integração ao GSA, intitulados como o Nearpod, o PlayPosit, o Socrative, o Quizlet Live, o Kahoot!, o Quizizz, o Padlet, o Canva for Education, o BitMoji, EquatIO - Math made digital, o Google Meet Grid View, o Nod - Reactions for Google Meet, o Tab Scissors e o Khan Academy. Alguns desses recursos são utilizados como tarefas dentro da GSA e outros, durante a aula online, realizada através de uma videoconferência com o Google Meet.

Alguns desses recursos digitais geram relatórios dos testes - através da metodologia ativa da gamificação ${ }^{13}$ - aplicados aos alunos, proporcionando um feedback da aprendizagem, enquanto outros recursos proporcionam uma atividade cooperativa entre os educandos. É importante salientar que essas atividades fomentam o protagonismo do aluno, uma vez que valorizam a sua ação, reflexão e colaboração e que demonstram à criança e ao adolescente que o isolamento social não impede a existência da participação coletiva para a resolução de problemas.

Os dados coletados para os relatórios são recolhidos pelas próprias plataformas e ficam disponíveis ao professor e a empresa Google, uma vez que a integração com a ferramenta GSA permite que tenha o acesso, pois as tarefas podem ser disponibilizadas diretamente na sala de aula virtual. Esses dados servem como um resumo geral para que o professor veja como está o andamento da aprendizagem do discente perante as atividades remotas.

13 Metodologias ativas: realização de atividades que promovem um engajamento do aluno, onde ele não é meramente um espectador da aprendizagem. Gamification (em inglês) pode ser definido como uma metodologia baseada, segundo KAPP (2002), pelo uso de características baseadas em jogos - tais como mecânica, estética e pensamento - com a finalidade de motivar e envolver as pessoas, resolver problemas e promover o aprendizado. 
É a partir desses dados que o docente e a Secretaria de Educação conseguem ver as informações dos alunos e o envolvimento deles nas tarefas digitais durante a quarentena. Cerca de $80 \%$ dos estudantes matriculados nas duas matérias aderiram ao ensino remoto, os outros $20 \%$ que não adotaram o ensino digital retiraram atividades impressas na escola, adaptadas pelos docentes.

No mês de junho, as escolas receberam como complemento os cadernos São Paulo faz escola, em que atividades pré-selecionadas pelo Governo do Estado de São Paulo foram organizadas e distribuídas não só para os alunos das escolas Estaduais, como também para os alunos das escolas da Prefeitura, seguindo as diretrizes da BNCC (Base Nacional Comum Curricular). Esses cadernos foram utilizados pelos professores como um complemento as atividades postadas no GSA.

O ensino na modalidade remota emergencial acarretou em um acúmulo de atividades para o docente, uma vez que todas as etapas do ensino acontecem por meio dessas ferramentas e plataformas. Essa mudança repentina na vida dos professores resultou em novos protocolos como o envio de relatórios semanais de teletrabalho, desenvolvimento de planos de aula e atividades para o ensino remoto digital como a gravação e edição de videoaulas, manuseio dos recursos digitais e plantões de dúvidas por meio de serviço de comunicação on-line. Tais funções exigiram do corpo docente um conhecimento específico que não fazia parte da atribuição do ensino presencial.

Um programa de inserção de tecnologia digital nas escolas da Prefeitura de Itanhaém foi criado em 2019 e intitulado Aprendizado do Futuro, em parceria com a Google, porém esse projeto visava o uso dessas tecnologias em sala de aula e não o treinamento para um ensino totalmente remoto. Esse projeto que consiste na inclusão de TDIC nas aulas presenciais - com a adesão ao GSA destaca-se no cenário nacional pelo uso de recursos tecnológicos, com programas como "Robótica Sustentável" e "Audiobooks" (ITANHAÉM, 2019). A Rede Municipal adquiriu kits de tablets, de Chromebooks e de Lousas Digitais e organizou capacitações para o uso do G Suite. 
Durante aquele ano, os docentes utilizaram as ferramentas digitais como um complemento das atividades presenciais, sendo que os discentes faziam o uso dos Chromebooks em sala de aula. Com o início da pandemia e a publicação do decreto com a suspensão das aulas presenciais, a Secretaria da Educação em conjunto com a empresa CONVEX ofereceu treinamentos para os docentes interessados em aprender a manusear as ferramentas digitais da Google. Após as capacitações, um novo cronograma foi criado para o início das atividades remotas (com alteração no calendário escolar), que até o momento segue sendo um desafio diário.

E mesmo diante das dificuldades como os acessos dos discentes às plataformas, problemas com a conexão à internet e acúmulo de funções, o ensino remoto ainda é uma das alternativas para manter o calendário escolar.

\section{Capitalismo de Vigilância e a Educação Vigiada}

O modo como utilizamos a internet foi moldado nas últimas décadas por empresas específicas como Google, Apple, Facebook, Amazon e Microsoft (GAFAM). Tais empresas funcionam como lentes com as quais enxergamos o ciberespaço. Talvez o exemplo mais emblemático seja a Google, que em 1998 ao lançar o buscador Google Search, definiu as bases para a coleta e a extração de informações, tornando a experiência humana uma fonte de dados e metadados que ao serem comercializados, modificaram estruturas econômicas, definiram a lógica do capitalismo de vigilância (ZUBOFF, 2019) e a governamentalidade algorítmica (ROUVROY E BERNS, 2013). Atualmente, a empresa Google faz parte do conglomerado Alphabet Inc. que investe em diversos setores como tecnologia, biotecnologia e automação residencial. Um desses setores, chamado Google for Education, desenvolve produtos específicos para o campo da educação.

A pandemia de COVID-19 acelerou certas práticas digitais como o trabalho a distância ou home office, uma alternativa para manter as atividades durante os momentos de lockdown, entretanto, esse protocolo que deveria ser emergencial pode se tornar mais uma ameaça aos direitos trabalhistas, reforçando o discurso 
de conectividade e disponibilidade ininterruptas, sobrepondo a carga de trabalho e os horários de descanso e lazer.

A ideologia do trabalhador empreendedor, "dono" do seu tempo, livre de barreiras temporais e espaciais é produto do período técnico-científico informacional (SANTOS, [1996] 2017) no qual a tecnologia é vista como uma solução mágica dentro do mundo globalizado. A fluidez do capital também exige a fluidez dos corpos, porém diante de uma pandemia é preciso recuar, manterse em isolamento e investir no desenvolvimento das TDIC e na conexão via internet.

É imprescindível lembrar que a gestão de uma rede, seja ela digital ou não, está diretamente relacionada ao poder e segundo Santos, "[...] a palavra poder deve ser aqui reconhecida no sentido que lhe dão Taylor e Thrift, isto é, a capacidade de uma organização para controlar os recursos necessários ao funcionamento de uma outra organização ([1996] 2017, p. 271)".

Portanto, empresas que já apresentam uma estrutura robusta em tecnologias digitais como as GAFAM tornam-se alternativas "fáceis" na busca de soluções imediatas. Porém, tal facilidade vem acompanhada de um custo que não está descrito nos contratos e que ainda é pouco debatido no cenário educacional. $\mathrm{O}$ valor dos dados e metadados produzidos por docentes e discentes nas plataformas gerenciadas por essas empresas.

A experiência humana datificada tornou-se o principal commodity do capitalismo de vigilância, termo cunhado por Shoshana Zuboff (2015, 2019), professora emérita da Universidade de Harvard, que dedicou grande parte da sua pesquisa para investigar essa mutação do sistema econômico.

Para empresas como a Google, o cruzamento de dados e metadados gera aquilo que Zuboff (2019) definiu como excedente comportamental14 (nossa tradução), ou seja, tudo aquilo que fazemos no ciberespaço é analisado pelos algoritmos

14 No original: behavioral surplus. 
dessas empresas que então são capazes de traçar perfis com precisão e influenciar comportamentos por meio de inteligência artificial.

Zuboff (2019) destaca a relação problemática entre usuários e empresas de tecnologia, definida por políticas de privacidade voláteis, modificadas de acordo com as necessidades do mercado. Tais políticas permitem que empresas como Google e Facebook façam uso dos dados de seus usuários de modo questionável. Nas palavras da autora,

O algoritmo da Google, baseado no cruzamento de dados, seleciona e ordena os resultados, e o algoritmo do Facebook, também baseado no cruzamento dos dados, seleciona e ordena o conteúdo do News Feed. Em ambos os casos, pesquisadores comprovaram que essa manipulação reflete os objetivos comerciais de cada empresa (ZUBOFF, 2019, p. 186, tradução nossa).

Para Zuboff, tal manipulação é uma ameaça ao Estado de direito e a democracia, uma vez que a venda de dados produzidos em determinadas plataformas pode influenciar escolhas políticas, como aponta o escândalo Cambridge Analytica, no qual a rede social Facebook vendeu dados de mais de 87 milhões de usuários (ISAAK e HANNA, 2018) para uma firma que trabalhou na campanha de Donald Trump durante as eleições estadunidenses de $2016^{15}$.

A lógica do capitalismo de vigilância foi naturalizada com o uso das redes sociais que enfatizavam o discurso da facilidade, conectividade e gratuidade. Os usuários eram capazes de interagir com seus amigos de um modo fácil e aparentemente gratuito, porém a moeda de troca por esses serviços sempre foi o resultado das experiências humanas produzidas durante essa interação.

No campo da educação não será diferente: a Google investe capital e tecnologia para se estabelecer como referência no espaço educacional, lançando produtos específicos para essa área, visando a extração de dados de milhões de docentes e discentes ao redor do mundo.

\footnotetext{
${ }^{15}$ Segundo arquivos apurados pelo jornal The Guardian. Disponível em: https://www.theguardian.com/news/series/cambridge-analytica-files. Acesso em: 15 jul .2020.
} 
No Brasil, o projeto Educação Vigiada, que envolve diversas instituições de pesquisa e ensino como a Universidade Federal do Pará e a iniciativa Educação Aberta, aponta uma ampla adoção de plataformas desenvolvidas pelas GAFAM no armazenamento de dados em instituições públicas.

Segundo os dados disponíveis no site, 67\% das instituições de ensino como Institutos Federais, SEDUCs, Universidades Federais e Estaduais fazem uso de serviço de e-mail ou outras plataformas produzidas pela Google, Apple, Facebook, Amazon ou Microsoft.

O principal problema, como aponta o projeto, é a relação obscura entre a oferta "gratuita" de serviços e o uso dos dados de professores, alunos e técnicos administrativos. A falta de uma legislação específica que proteja de maneira eficaz os dados dos usuários agrava ainda mais essa questão, uma vez que sem uma auditoria externa, essas empresas fazem suas próprias políticas de privacidade.

A pandemia de COVID-19 acelerou um processo que já estava em curso, como indicado ao longo relato de experiência, porém o caráter emergencial não permitiu um momento de reflexão e mobilização docente e discente para questionar a adoção dessas plataformas.

Michael Apple construiu uma interessante metáfora sobre a adoção de currículos prontos que facilitariam a vida do professor,

Quando os prédios educacionais estão pegando fogo, e eu como professor preciso escapar dele, e me são oferecidas duas janelas, em que a da direita diz 'aqui está o currículo multicultural para você professor' e a da esquerda são oferecidos textos e livros escritos numa linguagem que os professores não conhecem/dominam/usam, com o fogo chegando mais perto muitos professores acabam pulando pela janela da direita (APPLE, 2012, p.181).

O cenário do prédio pegando fogo não poderia ser mais atual quando comparado a pandemia de COVID-19, entretanto, não nos foi oferecida escolha entre plataformas e sistemas, os magnatas da tecnologia e governos já decidiram por nós. 


\section{Conchusão: $O$ capitalismo de vigilância será responsável pelo fim da liberdade de cátedra?}

A COVID-19, ao marcar o início do século XXI (cf Schwarcz, 2020), período de avanços tecnológicos sem precedentes, aponta o quão ineficazes ainda somos no combate de micro-organismos de ampla contaminação e altas taxas de mortalidade. Outrossim, coloca em xeque o sistema econômico que prioriza o lucro à vida e traz discussões como a proposta por Zizek:

Há alguns anos, Fredric Jameson chamou a atenção para o potencial utópico dos filmes sobre catástrofes cósmicas (um asteroide que ameaça a vida na Terra ou um vírus que mata a humanidade, por exemplo). Tal ameaça global dá origem à solidariedade global, nossas pequenas diferenças se tornam insignificantes, todos trabalhamos juntos para encontrar uma solução - e aqui estamos hoje, na vida real. O ponto não é sobre curtir sadicamente o sofrimento generalizado, porque ele ajudaria nossa causa: pelo contrário, o ponto é refletir sobre o triste fato de que precisemos de uma catástrofe para nos permitirmos repensar as características básicas da sociedade na qual vivemos (ZIZEK in AMADEO, 2020, p.23, tradução nossa).

Apesar de sermos parte de uma "aldeia global", a desigualdade no combate da pandemia demonstra o quanto a ideia de globalização é uma falácia que visa apenas a fluidez do capital e o enriquecimento de grandes empresas. Um exemplo foi a corrida global por equipamentos de proteção individual (EPI), como máscaras e luvas, na qual o governo dos Estados Unidos e empresas privadas estadunidenses tornaram a compra de EPI um leilão mundial, desbancando países como França, Brasil e Canadá16.

Infelizmente, a proposta de Zizek sobre uma transformação no sistema capitalista não se concretizou e o que vemos são milhões de desempregados, fruto dos severos cortes trabalhistas nas mais diversas áreas. Muitos desses desempregados são arrimo de família cujos filhos dependem da educação pública e da estrutura fornecida pelo Estado. Nesses núcleos familiares, o acesso

\footnotetext{
${ }^{16}$ DE ORTE, P. Brasil, que perdeu compra na China os EUA, está no meio de uma corrida global por suprimentos médicos. Disponível em:

$<$ https://oglobo.globo.com/mundo/brasil-que-perdeu-compra-na-china-para-os-euaesta-no-meio-de-uma-corrida-global-por-suprimentos-medicos-24348061>. Acesso em: 20 jul. 2020.
} 
à internet pode ser um sonho inalcançável e que impede o direito à educação emergencial.

Dentro do nosso recorte, $26 \%$ dos alunos não realizaram as tarefas escolares no ensino remoto durante os meses entre maio e julho. Nossa hipótese é que esses discentes não participaram das atividades por fatores ligados à falta de equipamentos adequados, falta de conexão a uma internet estável ou falta de suporte familiar. Outro fator derivante do desemprego crescente foi o acréscimo de $13 \%$ de novas matrículas em nossas turmas, todas advindas de escolas particulares.

É importante destacar que no Brasil, $79 \%$ dos cidadãos que ganham até um salário mínimo acessam a internet apenas pelo celular ${ }^{17}$, sendo que mais da metade o faz por meio de planos pré-pagos, com uma velocidade reduzida. Alguns desses planos oferecem navegação "gratuita" apenas em plataformas como Facebook ou Whatsapp, restringindo ainda mais o acesso à informação, fomentando a mineração de dados e naturalizando a lógica do capitalismo de vigilância.

Neste momento, quando adotamos um ensino remoto emergencial, o debate sobre uso de dados e privacidade dos usuários torna-se cada vez mais urgente. Como vimos, o município de Itanhaém já investia na adoção de TDIC voltadas para educação, portanto, uma mudança de paradigma estava em curso, entretanto, a pandemia acelerou-a e silenciou a voz dos docentes nas escolhas de sistemas digitais.

Anteriormente, as ferramentas digitais eram mais uma alternativa para diversificar o processo de aprendizagem, contudo, na atual situação de calamidade pública, a utilização desses sistemas se tornou obrigatório, sem que fosse oferecido recursos técnicos (acesso à banda larga) e treinamentos eficazes para todo corpo docente.

${ }_{17}$ Dados disponíveis em: <https://cetic.br>. Acesso em: 27 jul. 2020. 
Nesse contexto, nossa jornada de trabalho aumentou consideravelmente, uma vez que tivemos que investir tempo na aprendizagem das novas ferramentas tecnológicas, além de adaptar o ambiente doméstico, comprando materiais para transformar a casa em um espaço de trabalho. Isso acarretou em uma mudança na dinâmica familiar e com isso houve uma sobrecarga de afazeres, já que a mulher tem, histórica e socialmente, enraizada em seu papel o ideário de cuidadora.

Enquanto mulheres, indagamo-nos sobre como as divisões de trabalho ainda guardam desigualdades que são acentuadas no atual momento científicoinformacional. Enquanto professoras, questionamos a participação dos órgãos responsáveis na capacitação e distribuição de material de trabalho que possibilite acesso à internet.

Segundo a constituição brasileira, a gestão do ensino público deve ser democrática, considerar o pluralismo de ideias e de concepções pedagógicas, garantindo igualdade de acesso a todos ${ }^{18}$. Não obstante, a obrigatoriedade do uso de determinadas plataformas, faz com que o exercício do direito de escolha de concepções plurais durante a aprendizagem seja tolhido, uma vez que docentes e discentes estão reféns dos sistemas de uma única empresa, no caso desse relato a Google, que impõe a lógica do capitalismo de vigilância no ambiente escolar e faz com que a educação pública, um direito universal, esteja nas mãos de empresas privadas, para servir de fonte de extração de dados.

Lembremos que um dos objetivos do Ensino Fundamental, segundo as Leis de Diretrizes e Bases (LDB), é "a compreensão do ambiente natural e social, do sistema político, da tecnologia, das artes e dos valores em que se fundamenta a sociedade”, portanto, cabe a esse nível da Educação Básica uma expressiva parcela na formação do cidadão e o debate sobre como o fazemos e quais instrumentos utilizamos também falam sobre os valores que propagamos.

\footnotetext{
${ }^{18}$ Disponível em: < https://www.senado.leg.br/atividade/const/con1988/con1988_18.02.2016/art_206_. asp> . Acesso em: 26 jul. 2020.
} 
A imposição de determinadas práticas, principalmente aquelas relacionadas às TDIC mencionadas nesse relato, faz com que a Escola perca seu caráter de formação crítica e reflexiva, sendo tomada por uma lógica tecnicista na qual os dados valem mais que a experiência.

Nesse momento, é preciso dar voz a pensadores como Jorge Larossa Bondia (2002) que defende uma educação baseada na experiência, destacando que o processo de aprendizagem demanda tempo e reflexão. Mesmo antes da pandemia, vivíamos uma aceleração típica de nosso período técnico-científico informacional que não nos permitia tempo para debater essa colonização digital da educação por meio das GAFAM. Se não encontrarmos tempo agora, talvez em alguns anos seja tarde demais.

\section{Referências}

AMADEO, P. (ed.). Sopa de Wuhan: pensamiento contemporáneo en tiempos de pandemias. Editorial ASPO (Aislamiento Social Preventivo y Obligatorio), 2020.

BRASIL, LEI $\mathrm{N}^{\circ}$ 13.979, DE 6 DE FEVEREIRO DE 2020. Dispõe sobre as medidas para enfrentamento da emergência de saúde pública de importância internacional decorrente do coronavírus responsável pelo surto de 2019. Diário Oficial da União, Brasília, DF, o7 fev. 2020, ed. 27, seção: 1, p. 1, 2020.

BRASIL, Ministério da Educação. Diretrizes Curriculares Nacionais de Educação Básica. Brasília: MEC, SEB, DICEI, 2013.

BRASIL, Ministério da Saúde. Agência Saúde. Disponível em: <https://www.saude.gov.br/noticias/agencia-saude/46435-brasil-confirmaprimeiro-caso-de-novo-coronavirus>. Acesso em: 13 jul. 2020.

BONDIA, J. L. Notas sobre a experiência e o saber de experiência. Revista Brasileira de Educação, n.19, p. 20-28, 2002.

EDUCAÇÃO ABERTA; UFPA. Educação vigiada. Disponível em:

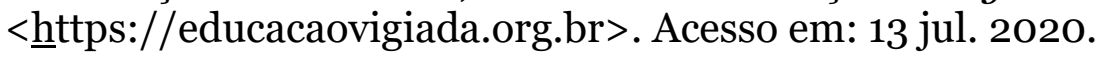

FOUCAULT. M. Vigiar e punir: nascimento da prisão. Tradução Raquel Ramalhete. Petrópolis: Vozes, 288p, 1987.

DE JESUS, J. C.; MYRRHA, L. Os afazeres domésticos antes e depois da pandemia: desigualdades sociais e de gênero. Programa de Pós-Graduação em Demografia da UFRN. Disponível em: 
<ttps://demografiaufrn.net/2020/o7/16/afazeres-domesticos-antes-edepois/>. Acesso em: 24 jul. 2020.

HAN, B-C. No Enxame: perspectivas do digital. Editora Vozes Limitada, 2018.

HARARI, Y. N. 21 Lições para o Século 21. Editora Companhia das Letras, 2018.

HE, G.; PAN, Y.; TANAKA, T. The short-term impacts of COVID-19 lockdown on urban air pollution in China. Nature Sustainability, p. 1-7, 2020.

ISAAK, J.; HANNA, M. J. "User Data Privacy: Facebook, Cambridge Analytica, and Privacy Protection". Computer, v. 51, n. 8, p. 56-59, 2018. Disponível em: $<$ https://ieeexplore.ieee.org/stamp/stamp.jsp?tp=\&arnumber=8436400\&isnu mber $=8436391>$. Acesso em: 13 jul. 2020.

ITANHAÉM (Município). Decreto No 3.899, de 16 de março de 2020. Dispõe sobre a adoção de medidas temporárias e emergenciais de prevenção de contágio pelo COVID-19 (Novo Coronavírus), no âmbito da Administração Direta e Indireta do Município de Itanhaém, e dá outras providências. Registrado em livro próprio. Departamento Administrativo. São Paulo, p. 1-3. Disponível em: <http://www.itanhaem.sp.gov.br/legislacaomunicipal/anexos/Dec-3914.pdf>. Acesso em: 13 jul. 2020.

ITANHAÉM (Município). A tecnologia é uma aliada na sala de aula. Boletim oficial, Itanhaém, n. 569, p. 5, 10 a 15 de outubro de 2019. Disponível em: <http://www2.itanhaem.sp.gov.br/boletim-oficial/edicao-569/>. Acesso em: 15 jul. 2020.

KAPP, K. M. "The gamification of learning and instruction: game-based methods and strategies for training and education”. John Wiley \& Sons, 2012.

LAM, T. et al. Identifying SARS-CoV-2-related coronaviruses in Malayan pangolins. Nature, p. 1-4, 2020.

PAINEL CONASS COVID-19. Disponível em: <https://www.conass.org.br/painelconasscovid19/>. Acesso em: 28 de jul. 2020.

SÃO PAULO (Estado). DECRETO No 64.881, DE 22 DE MARC, D DE 2020. Decreta quarentena no Estado de São Paulo, no contexto da pandemia do COVID-19 (Novo Coronavírus), e dá providências complementares. Diário Oficial do Estado de São Paulo, v. 130, n. 57, 2020.

SILVA, M. V. (e outros). Contradições e ambiguidades do currículo e das políticas educacionais contemporâneas - entrevista com Michael Apple. Currículo sem fronteiras, v.12, n.1, p. 175-184, Jan/Abr 2012. Disponível em: <https://www.curriculosemfronteiras.org/vol12iss1articles/silva-marquesgandin.pdf $>$. Acesso em: 15 jul. 2020.

SANTOS, M. A Natureza do Espaço: Técnica e Tempo. Razão e Emoção. São Paulo: Editora da Universidade de São Paulo, [1996] 2017. 
SANTOS (Município). Decreto No 8.889, de 16 de março de 2020. Estabelece medidas de contingência para prevenção do coronavírus no âmbito da administração pública direta e indireta do município de santos, e dá outras providências. Registrado no livro competente. Departamento de Registro de Atos Oficiais do Gabinete do Prefeito Municipal São Paulo, p. 1-2. Disponível em: $\quad<$ https://www.santos.sp.gov.br/?q=institucional/legislacoes-covid $>$. Acesso em: 13 jul. 2020.

SCHWARCZ, L. Quando acaba o século XX. Breve companhia/ensaio. Companhia das Letras, 2020. Edição kindle.

ROUVROY A.; BERNS T. Governamentalidade algorítmica e perspectivas de emancipação: o díspar como condição de individuação pela relação?. In: BRUNO, F. et al. Tecnopolíticas da Vigilância: Perspectivas da margem. Tradução Antonio Holzmeister Cruz e Bruno Cardoso. São Paulo: Boitempo, [2013] 2018.

WU, F. et al. A new coronavirus associated with human respiratory disease in China. Nature, v. 579, n. 7798, p. 265-269, 2020.

ZUBOFF, S. Big other: Capitalismo de vigilância e perspectivas para uma civilização de informação. In: BRUNO, F. et al. Tecnopolíticas da Vigilância: Perspectivas da margem. Tradução Antonio Holzmeister Cruz e Bruno Cardoso. São Paulo: Boitempo, [2015] 2018.

ZUBOFF, S. The Age of Surveillance Capitalism. v. 1. New York: PublicAffairs, 2019. 